\title{
Efeito do método de extração na composição química e nas propriedades funcionais do amido de inhame (Dioscorea alata)
}

\section{Effects of extraction method on chemical composition and functional properties of yam starch (Dioscorea alata)}

\author{
Juliana Suriano Nascimento Liporacci ${ }^{1}$; Suzana Mali2 ${ }^{*}$; Maria Victória Eiras Grossmann ${ }^{3}$
}

\section{Resumo}

Tubérculos de inhame (Dioscorea alata) constituem-se em uma fonte não convencional de amido. O amido de inhame tem sido estudado como um polímero promissor na confecção de biofilmes por conter cerca de 30\% de amilose, polímero responsável pela capacidade de formação de filmes nos amidos. Os amidos obtidos dos tubérculos de inhame foram extraídos por dois diferentes métodos e as características químicas e funcionais das amostras foram analisadas. O primeiro método, descrito por Alves, Grossmann e Silva (1999) foi executado em seis dias, gerando 7\% de amido com grau de pureza acima de $95 \%$. O segundo método, descrito por Cereda et al. (2003), rendeu 13\% de amido com grau de pureza de $84 \%$ e foi realizado em três dias. Os amilogramas Brabender mostraram que as pastas de amido apresentaram estabilidade sob tratamento térmico, com menores valores de viscosidade para os amidos obtidos pelo segundo método de extração. A capacidade de formação de filmes das amostras extraídas pelos dois métodos foi similar, formando-se filmes com alta resistência mecânica, porém o amido obtido através do segundo método formou filmes mais opacos. Para adaptação à indústria, o segundo método de extração pareceu ser o mais adequado, porque o rendimento foi maior e requereu menos tempo.

Palavras-chave: Extração, amido de inhame, biofilmes

\begin{abstract}
Yam tubers (Dioscorea alata) are a non-traditional starch source. Yam starch had been studied as a promising polymer for biofilm production because it contains about $30 \%$ of amylose, and amylose is responsible for the film-forming capacity of starches. Starches obtained from yam tubers were extracted employing two different methods and its chemical and functional characteristics and film forming capacity were analysed. The first method, described by Alves, Grossmann e Silva (1999) was executed in 6 days, generating from yam tubers $7 \%$ of yam starch with purity grade up to $95 \%$. The second method, described by Cereda et al. (2003), yielded 13\% of yam starch with purity grade around $84 \%$ and was developed in three days. Brabender amylograms showed that starch pastes maintained stability under heat treatment with lower viscosity values to the starch obtained by second extraction method. In film forming capacity, both starches presented similar results, forming films with high tensile strength, but the starch obtained by second extraction method formed films with high opacity values. To industry use, the second method seemed to be more appropriate, because had a higher yield and required fewer time.
\end{abstract}

Key words: Extraction, yam starch, biofilms

1 Aluna de Graduação do Curso de Química da Universidade Estadual de Londrina

2 Farmacêutica - Bioquímica, Doutora em Ciência de Alimentos e Bolsista CAPES - PRODOC do Departamento de Tecnologia de Alimentos e Medicamentos, CCA, UEL

3 Docente do Programa de Mestrado e Doutorado em Ciência de Alimentos do Departamento TAM, CCA, UEL.

* Autor para correspondência. 


\section{Introdução}

O crescente acúmulo de lixo não biodegradável, aliado à dificuldade de reciclagem da maioria das embalagens sintéticas disponíveis, têm incentivado as pesquisas no desenvolvimento de materiais biodegradáveis com características que permitam a sua utilização em embalagens. As razões que têm levado alguns biopolímeros ao centro de interesse em pesquisas são: a preservação das fontes não renováveis de energia, a redução do volume de lixo e a proteção do clima pela redução do dióxido de carbono liberado no meio ambiente pela incineração de lixo (LÖRCKS, 1998).

A utilização de filmes e revestimentos comestíveis e/ou biodegradáveis para a proteção de alimentos já foi empregada em tempos passados de forma empírica. O revestimento de laranjas e limões com ceras, para retardar a perda de água destes frutos, foi praticada na China, entre os séculos 12 e $13 . \mathrm{Na}$ Inglaterra do século 16, era comum a prática de se revestir alimentos com materiais gordurosos para diminuir a velocidade de desidratação destes produtos (KUUTTI et al., 1998).

Ao longo do século 19 foram desenvolvidos alguns tipos de revestimentos à base de gelatina para preservação de carnes, como proposto nas patentes de Harvard e Harmony, de 1869, e de Morris e Parker, de 1895 (KESTER; FENNEMA, 1986). Em meados de 1930 já estava disponível comercialmente um revestimento de parafina para frutos cítricos, utilizado para retardar a perda de água e no início dos anos 50 uma emulsão de cera de carnaúba era empregada para revestir frutos e vegetais frescos (KAPLAN, 1986).

Em meados dos anos 70, as pesquisas se voltaram para a introdução de amido a matrizes poliméricas sintéticas, na proporção de 5 a $20 \%$, levando à obtenção de plásticos considerados biofragmentáveis, mas não totalmente biodegradáveis (GUILBERT; GONTARD, 1995). Nos últimos anos, há o interesse no desenvolvimento de materiais termoplásticos compostos essencialmente por amido (LÖRCKS, 1998; SOUZA; ANDRADE, 2000), envolvendo a adição de plastificantes para melhorar as propriedades mecânicas. Os plastificantes devem ser compatíveis com o biopolímero e, geralmente, são adicionados na proporção de 10 a 60 g/g matéria seca, dependo do grau de rigidez do material (GONTARD; GUILBERT; CUQ, 1993).

Um dos primeiros filmes plásticos biodegradáveis utilizados foi o celofane (obtido a partir do xantato de celulose), material flexível, transparente e com boas propriedades mecânicas, porém, sensível à umidade. Desde a introdução dos polímeros sintéticos na produção de embalagens, em 1950, as vendas de celofane chegaram a cair $90 \%$ (JENKINS; HARRINGTON, 1991).

$\mathrm{O}$ amido pode ser obtido de diversas fontes vegetais, como cereais, raízes e tubérculos, e também de frutas e legumes, no entanto, a extração em nível comercial de amido se restringe aos cereais, raízes e tubérculos. O amido é o polissacarídeo de reserva dos vegetais e está armazenado sob a forma de grânulos, que apresentam um certo grau de organização molecular, o quê confere aos mesmos um caráter parcialmente cristalino, ou semicristalino, com graus de cristalinidade que variam de 20 a $45 \%$ (YOUNG, 1984).

$\mathrm{O}$ amido é formado por dois tipos de polímeros de glucose, a amilose e a amilopectina, com estruturas e funcionalidade diferentes. A amilose é um polímero linear com unidades de D-glucose ligadas por ligações $\alpha$-(1-4), com grau de polimerização de 200 a 3000, dependendo da fonte do amido. A amilopectina é um polímero altamente ramificado, com unidades de $\mathrm{D}$ glucose ligadas através de ligações $\alpha-(1-4)$ e as ramificações em $\alpha-(1-6)$ (ELLIS et al., 1998). Variações nas proporções entre estes componentes podem resultar em grânulos de amido com propriedades físico-químicas e funcionais muito diferentes, que podem afetar as suas aplicações industriais. 
A aplicação do amido na confecção de biofilmes se baseia nas propriedades químicas, físicas e funcionais da amilose para formar géis e na sua capacidade para formar filmes (YOUNG, 1984). As moléculas de amilose em solução, devido à sua linearidade, tendem a se orientar paralelamente, aproximando-se o suficiente para que se formem pontes de hidrogênio entre hidroxilas de cadeias de amilose adjacentes. Como resultado, a afinidade do polímero por água é reduzida, favorecendo a formação de pastas opacas e filmes resistentes (WURZBURG, 1986).

Dentre as espécies de cará ou inhame, tubérculos do gênero Dioscorea, as mais cultivadas no Brasil são $D$. alata, D. caynensis e D. rotundata, direcionadas ao consumo in natura, principalmente devido à falta de processos de industrialização, que se dá pelo alto nível de mucilagem que dificulta a liberação do amido do tecido vegetal e à falta de popularização das suas qualidades nutricionais e funcionais (ALVES, 2000). Todos estes fatores, aliados, levam à uma subutilização destes tubérculos como fonte de amido. Diante disto, os objetivos do presente trabalho foram comparar duas diferentes metodologias para a extração do amido de inhame considerando-se tempo, rendimento e facilidade de extração, assim como, estabelecer as características funcionais dos produtos e a sua capacidade de formação de filmes.

\section{Material e Métodos}

\section{Material}

Os tubérculos de inhame (Dioscorea alata) utilizados foram produzidos na região de Londrina$\mathrm{PR}$ e foram previamente selecionados quanto à ausência de injúrias mecânicas e patológicas. Todos os reagentes empregados apresentavam Pureza Analítica (PA).

\section{Métodos}

- Extração e caracterização do amido de inhame

Para a extração de amido de inhame foram testadas as metodologias descritas por Alves, Grossmann e Silva (1999) e por Cereda et. al. (2003). As extrações de amido foram realizadas em batelada, nos laboratórios do Departamento de Tecnologia de Alimentos e Medicamento da Universidade Estadual de Londrina.

No estudo da extração de amido, empregando-se a metodologia de Alves, Grossmann e Silva (1999), foram utilizados dois lotes de $15 \mathrm{~kg}$ de tubérculos de inhame devidamente lavados e pesados. Após descascamento, os tubérculos foram triturados em processador de alimentos com solução de metabissufito de sódio $0,1 \%(\mathrm{p} / \mathrm{v})$ e, na seqüência, filtrados em sacos de nylon (com abertura da malha próxima de 60 mesh). $\mathrm{O}$ filtrado recolhido, contendo a fração amilácea, foi lavado quatro vezes e deixado decantar, no período de 2 dias, com solução de metabissufito de sódio $0,1 \%(\mathrm{p} / \mathrm{v})$ e, então, lavado com solução de hidróxido de sódio 0,15 e, em seguida, com solução $0,10 \%$ (p/v). Em seguida, o amido foi lavado várias vezes com água até o $\mathrm{pH}$ se aproximar de 7,0 (cerca de 2 dias), foi recolhido e lavado na presença de álcool $70 \%(\mathrm{p} / \mathrm{v})$. O material resultante foi seco em estufa com circulação e renovação de ar (Tecnal 394-3 / Piracicaba - SP) sob temperatura de $40^{\circ} \mathrm{C}$, tamisado (100 mesh) e embalado em sacos de BOPP (Polipropileno Bi-orientado) até a realização das análises. Todo o procedimento foi executado em 6 dias.

No estudo da extração de amido, empregando-se a metodologia descrita por Cereda et. al. (2003), foram utilizados dois lotes de $10 \mathrm{~kg}$ de tubérculos de inhame lavados, pesados e então, descascados. Os tubérculos foram triturados com uma solução $10 \%$ de oxalato de amônia/ácido oxálico (1:1). O material foi filtrado em sacos de náilon (com abertura da malha próxima de $60 \mathrm{mesh}$ ) e, em seguida, peneirado em tamis de 100 mesh. A suspensão de amido, com pH 
próximo de 2,0, foi tratada com uma solução de $\mathrm{NaOH}$ 0,1 mol.L $\mathrm{L}^{-1}$ até atingir $\mathrm{pH}$ 6,0. O amido foi decantado por uma noite, suspenso mais uma vez em água destilada e novamente decantado. $\mathrm{O}$ material recolhido foi seco em estufa com circulação e renovação de ar (Tecnal 394-3 / Piracicaba - SP) sob temperatura de $40^{\circ} \mathrm{C}$, tamisado (100 mesh) e embalado em sacos de BOPP (Polipropileno Biorientado) até a realização das análises. Todo o procedimento foi executado em 3 dias.

O rendimento de cada extração foi calculado como porcentagem de massa de amido obtida, com umidade de $14 \%$, em relação à massa bruta de tubérculos empregada, com a sua umidade original (cerca de $70 \%$ ). Os amidos obtidos foram caracterizados quanto aos seus teores de amilose e amilopectina, determinados simultaneamente de acordo com Landers, Gbur e Sharp (1991) e, quanto aos seus teores decinzas, proteínas, lipídios, amido e umidade de acordo com os métodos oficiais da AOAC (1995).

As propriedades de pasta do amido de inhame foram avaliadas empregando-se Viscógrafo Brabender (Pt 100, Duisburg, Alemanha). Suspensões aquosas de amido $(6 \% \mathrm{bs})$ foram aquecidas de $30 \mathrm{a}$ $95^{\circ} \mathrm{C}$ com taxa de aquecimento de $1,5^{\circ} \mathrm{C} / \mathrm{min}$ e agitação constante, mantidas a $95^{\circ} \mathrm{C}$ por 10 minutos e, então, resfriadas a $50^{\circ} \mathrm{C}$ com taxa de aquecimento de $1,5^{\circ} \mathrm{C} / \mathrm{min}$ e agitação constante. De acordo com Hoseney (1991), os parâmetros normalmente determinados para interpretação das propriedades de pasta através dos viscoamilogramas são: a) viscosidade inicial (valor de viscosidade da suspensão (Unidades Brabender - U.B.), no início do ciclo de aquecimento $\left.\left(30^{\circ} \mathrm{C}\right)\right)$, b) temperatura de pasta (temperatura em ${ }^{\circ} \mathrm{C}$ correspondente ao ponto onde se inicia a formação da curva do amilograma (aumento de $20 \mathrm{UB}$ na linha de base), c) viscosidade inicial e final a $95^{\circ} \mathrm{C}$ (valor das viscosidades na temperatura de $95^{\circ} \mathrm{C}$, antes e após 10 minutos nesta temperatura), d) viscosidade final (UB) na temperatura final de resfriamento $\left(50^{\circ} \mathrm{C}\right)$.
- Análise estatística

Cada extração do amido foi realizada em dois diferentes lotes de tubérculos, constituindo, portanto, duas repetições genuínas do experimento. Para análise estatística dos resultados obtidos foi empregado o programa computacional Statistica versão 5.0 (Statsoft - Oklahoma - USA). Foi empregado teste de Tukey (nível de significância de 5\%) para comparação de médias e análise do desvio-padrão.

\section{Resultados e Discussão}

As composições centesimais das amostras de amido obtidas através das duas metodologias estão descritas na Tabela 1. Pode-se notar que não houve diferença significativa (teste de Tukey, $\mathrm{p} £ 0,05$ ) quando o mesmo método de extração foi empregado para diferentes lotes de tubérculos (Tabela 1), exceto para o teor de cinzas das amostras obtidas pelo método 2. Observou-se que os teores de carboidratos e de amido das amostras obtidas através do método 1 foram significativamente maiores do que os das amostras obtidos pelo método 2 (Tabela 1). Isto pode ser explicado pelo maior número de lavagens realizadas durante a execução do método 1 , fornecendo amostras de amido mais puras dos que as obtidas pelo método 2 .

A Legislação Brasileira (BRASIL, 1978) não apresenta padrão de identidade e qualidade para o amido de inhame, no entanto, comparando-se os dados obtidos neste trabalho com os padrões estabelecidos para amido de mandioca e de batata, pode-se notar que a pureza (Tabela 1), tanto das amostras de amido obtidas através do método 1 (95 e $96 \%$ para os lotes 1 e 2), quanto das amostras de amido obtidas através do método 2 ( 82 e $84 \%$ para os lotes 1 e 2), atende os níveis recomendados, que devem ser de no mínimo $80 \%$.

O teor de amilose e amilopectina dos amidos obtidos nas duas extrações foi similar, isto é, $30 \%$ de amilose e $70 \%$ de amilopectina. Valores similares 
também foram obtidos por Alves, Grossmann e Silva (1999), Karam (2003) e Mali et al. (2004), confirmando-se o teor médio de amilose do amido de inhame, importante para a confecção de filmes e revestimentos biodegradáveis.

Quando se compara o rendimento de amido tendo como base o peso total de tubérculos com casca (Tabela 1), foi obtida uma média de $7,12 \%$ de rendimento de amido com $14 \%$ de umidade utilizando- se o método 1 , enquanto que o rendimento empregando-se o método 2 foi significativamente maior, com valores de $13 \%$ de rendimento em amido com $14 \%$ de umidade, diferença esta que também se explica pelo maior número de lavagens realizadas pelo método 1, que resultou em maiores perdas de material. Daiuto, Cereda e Vilpoux (2002) obtiveram rendimento de $18 \%$ empregando o método 2 , valor superior do obtido neste trabalho.

Tabela 1. Composição química dos amidos de inhame obtidos por diferentes métodos de extração.

\begin{tabular}{ccccc}
\hline & \multicolumn{2}{c}{${\text { Método } 1^{\mathrm{a}}}^{\mathrm{a}}$ Método 2 $^{\mathrm{b}}$} \\
\hline $\begin{array}{c}\text { Componente } \\
(\% \text { base seca })^{\mathrm{c}}\end{array}$ & Lote 1 & Lote 2 & Lote 1 & Lote 2 \\
\hline Cinzas & $0,12 \pm 0,03 \mathrm{a}$ & $0,23 \pm 0,15 \mathrm{a}$ & $0,55 \pm 0,08 \mathrm{c}$ & $0,32 \pm 0,02 \mathrm{~b}$ \\
Proteínas & $0,36 \pm 0,01 \mathrm{a}$ & $0,44 \pm 0,01 \mathrm{a}$ & $3,99 \pm 0,52 \mathrm{~b}$ & $3,73 \pm 0,16 \mathrm{~b}$ \\
Lipídios & $0,30 \pm 0,02 \mathrm{a}$ & $0,29 \pm 0,01 \mathrm{a}$ & $2,52 \pm 0,62 \mathrm{~b}$ & $2,15 \pm 0,52 \mathrm{~b}$ \\
Carboidratos ${ }^{\mathrm{d}}$ & $99,22 \pm 0,14 \mathrm{a}$ & $99,05 \pm 0,14 \mathrm{a}$ & $92,37 \pm 0,59 \mathrm{~b}$ & $93,80 \pm 0,66 \mathrm{~b}$ \\
Amido & $95 \pm 4 \mathrm{a}$ & $96 \pm 5 \mathrm{a}$ & $82 \pm 5 \mathrm{~b}$ & $84 \pm 4 \mathrm{~b}$ \\
\hline
\end{tabular}

a - Método de Alves, Grossmann e Silva (1999), b- Método de Cereda et al., 2003.

c - Letras minúsculas diferentes, na mesma linha, se referem a diferença significativa entre as amostras (Teste de Tukey, $\mathrm{p} £ 0,05),{ }^{\mathrm{d}}-$ Calculados por diferença.

A Figura 1 ilustra que o perfil amilográfico das amostras de amido obtidas pelos dois métodos foi similar, no entanto, o material obtido através do método 1 mostrou maiores valores de viscosidade, $\mathrm{o}$ que, provavelmente, aconteceu em função de seu maior grau de pureza.

O perfil de viscosidade do amido (Figura 1 e Tabela 2) confirma o comportamento já descrito por outros autores (ELLIS et al., 1998; ALVES, 2000; KARAM, 2003), isto é, alta temperatura de pasta $\left(75-76^{\circ} \mathrm{C}\right)$ quando comparada a outros amidos de tubérculos como a mandioca, que tem temperatura de pasta em torno de $61^{\circ} \mathrm{C}$, e ainda, ausência de pico de viscosidade máxima e estabilidade das suspensões durante o ciclo de aquecimento em alta temperatura, sugerindo, de acordo com Hoover (2001), a presença de ligações fortes no interior do grânulo. De acordo com Gebre-Mariam e Schmidt (1998), o constante aumento de viscosidade do amido de inhame durante a isoterma de aquecimento no viscógrafo pode ser atribuído à falta de água para atuar como lubrificante entre os grânulos intumescidos.

De acordo com Jane et al. (1999) as propriedades de pasta de amidos são afetadas pelo conteúdo de amilose e pela distribuição da amilopectina com relação ao comprimento das cadeias ramificadas. Entretanto, esses autores observaram também que o aumento do conteúdo de amilose aumenta significativamente a temperatura de pasta e decresce o pico de viscosidade no aquecimento, informações estas convergentes com os comportamentos obtidos neste estudo, já que o amido de inhame apresentou $30 \%$ de amilose, conteúdo superior à maioria dos amidos nativos. 


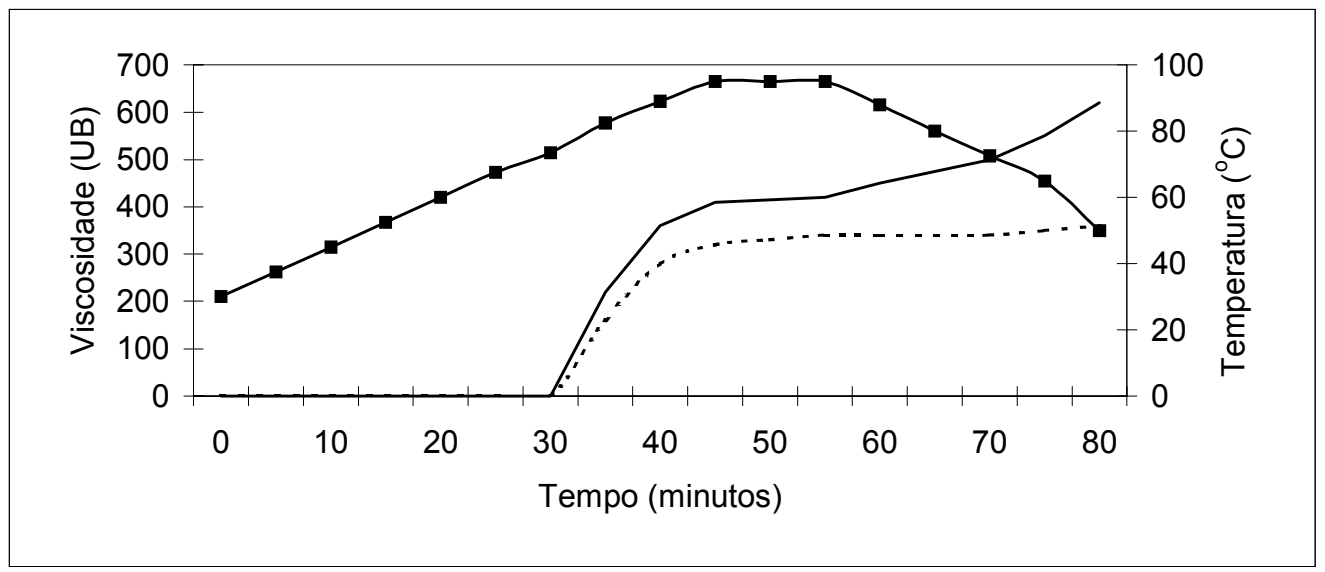

Figura 1. Perfil amilográficos dos amidos obtidos através dos métodos de extração 1 (—) e 2 (------). A linha com marcadores ( $\mathbf{\square})$ indica a variação de temperatura durante o teste.

Tabela 2. Parâmetros amilográficos dos amidos de inhame obtidos por diferentes métodos de extração.

\begin{tabular}{lcccc}
\hline & \multicolumn{2}{c}{ Método 1 ${ }^{\mathrm{a}}$} & \multicolumn{2}{c}{ Método 2 } \\
\hline \multicolumn{1}{c}{ Parâmetro ${ }^{\mathrm{c}, \mathrm{d}}$} & Lote 1 & Lote 2 & Lote 2 \\
\hline Viscosidade inicial (UB) & $0 \mathrm{a}$ & $0 \mathrm{a}$ & 0 & 0 \\
Temperatura de pasta $\left({ }^{\circ} \mathrm{C}\right)$ & $76 \mathrm{a}$ & $75 \mathrm{a}$ & $76 \mathrm{a}$ & $76 \mathrm{a}$ \\
Viscosidade inicial a $95^{\circ} \mathrm{C}$ (UB) & $380 \mathrm{a}$ & $410 \mathrm{a}$ & $320 \mathrm{~b}$ & $300 \mathrm{~b}$ \\
Viscosidade $95^{\circ} \mathrm{C}$ (final) (UB) & $380 \mathrm{a}$ & $420 \mathrm{a}$ & $340 \mathrm{~b}$ & $315 \mathrm{~b}$ \\
Viscosidade final a $50^{\circ} \mathrm{C}$ (UB) & $580 \mathrm{a}$ & $610 \mathrm{a}$ & $360 \mathrm{~b}$ & $340 \mathrm{~b}$ \\
\hline
\end{tabular}

a - Método de Alves, Grossmann e Silva (1999), ${ }^{\text {b }}$ Método de Cereda et al., 2003.

C - O coeficiente de variação médio das análises foi de $10 \%$.

d- Letras minúsculas diferentes, na mesma linha, se referem a diferença significativa entre as amostras (Teste de Tukey, $\mathrm{p} \leq 0,05)$.

As pastas de amido de inhame apresentaram maiores valores de viscosidade na etapa final do teste $\left(50{ }^{\circ} \mathrm{C}\right)$ do que na etapa de aquecimento (Figura $1 \mathrm{e}$ Tabela 2), conseqüentemente, pode ser assumido que sob resfriamento a viscosidade aumenta devido à elevada tendência de retrogradação da fração de amilose. De acordo com Alves, Grossmann e Silva (1999), Karam (2003) e Mali et al. (2004), o amido de inhame, em função do seu teor médio de amilose, em torno de $30 \%$, tem alta taxa de retrogradação, com cerca de $40 \%$ de perda de peso em géis armazenados por $24 \mathrm{~h}$.
Quanto à capacidade de formação de filmes, os amidos obtidos através dos dois métodos de extração apresentaram capacidade de formação de filme, formando filmes contínuos e resistentes, no entanto, devido à maior concentração de lipídios e cinzas, o amido obtido através do método 2 apresentou opacidade, avaliada visualmente, ligeiramente maior. Quanto à resistência mecânica, não houve diferença significativa na resistência à tração dos materiais confeccionados exclusivamente de amido, que apresentaram cerca de $80 \mathrm{~N}$ de resistência máxima sob tração. 


\section{Conclusões}

As duas metodologias estudadas neste trabalho podem ser empregadas para a extração de amido de inhame, com a obtenção de materiais com propriedades funcionais similares, no entanto, com diferentes graus de pureza e tempos de processamento. A extração de amido de inhame através do método 1, descrito por Alves, Grossmann e Silva (1999) requereu mais tempo, o rendimento foi menor, no entanto, o amido obtido apresentou alto grau de pureza. O método 2, descrito por Cereda et al (2003), requereu a metade do tempo, resultou em maior rendimento, porém o amido apresentou menor pureza quando comparado com as amostras obtidas pelo método 1. As amostras de amido de inhame, obtidas através dos dois métodos de extração, apresentaram a capacidade de formar filmes, no entanto, as amostras de amido obtidas pelo método 2 formaram filmes mais opacos, com maior contaminação de lipídios e cinzas. Portanto, dependendo da aplicação do amido, qualquer uma das metodologias pode ser empregada. Para adaptação para a indústria, o método de extração descrito por Cereda et al. (2003) pareceu ser o mais adequado, porque o rendimento foi maior e requereu menos tempo.

\section{Agradecimentos}

Ao Programa Capes/ProDoc.

\section{Referências}

ALVES, R. M. L. Caracterização de ingredientes obtidos de cará (Dioscorea alata) e potencial aplicação industrial. 2000. Tese (Doutorado em Ciência de Alimentos) - Universidade Estadual de Londrina, Londrina, 2000.

ALVES, R. M. L.; GROSSMANN, M. V. E.; SILVA, R. S. S. F. Pre-gelatinized starch of Dioscorea alata-functional properties. Food Chemistry, London, v. 67, n. 2, p. 123127, 1999.

AOAC. Official Methods of Analysis. Washington, 1995.
BRASIL. Resolução 12/78 da Comissão Nacional de Normas e Padrões para Alimentos. Aprova as NORMAS TÉCNICAS ESPECIAIS, do Estado de São Paulo, revistas pela CNNPA, relativas a alimentos (e bebidas), para todo território brasileiro. Diário Oficial da República Federativa do Brasil, Brasília, 1978.

CEREDA, M. P.; DAIÚTO, E. R.; LEONEL, M.; SILVEIRA, S. R. S. Avaliação da qualidade da fécula de inhame (Dioscorea $\mathrm{sp}$ ) obtida por diferentes processos de extração. In: SIMPÓSIO EM CIÊNCIA DE ALIMENTOS, 2003, Florianópolis. Anais... Florianópolis: Universidade Federal de Santa Catarina, 2003. p. 866-870.

DAIUTO, E. R.; CEREDA, M. P.; VILPOUX, O. F. Extração de amido de inhame (Dioscorea alata). In: SIMPÓSIO NACIONAL SOBRE AS CULTURAS DO INHAME E DO TARO, 2., 2002, João Pessoa. Anais... João Pessoa: Secretaria de Agricultura, Irrigação e Abastecimento, Empresa Estadual de Pesquisa Agropecuaria da paraíba e Ministerio da Agricultura, Pecuaria e Abastecimento, 2002. p. 120 .

ELLIS, R.P.; COCHRANE, M.P.; DALE, M. F.B.; DUFFUS, C. M.; LYNN, A.; MORRISON, I. M.; PRENTICE, R. D. M.; SWANSTON, J. S.; TILLER, S. A. Starch production and industrial use (Review). Journal of the Science of Food and Agriculture, Sussex, v. 77, n. 3, p. 289-311, 1998.

GEBRE-MARIAM, T.; SCHMIDT, P. C. Some physicochemical properties of dioscorea starch from Ethiopia. Starch/Stärke, Weinheim, v. 50, n. 6, p. 241-246, 1998.

GONTARD, N.; GUILBERT, S.; CUQ, J. L. Water and glycerol as plasticizers affect mechanical and water vapor barrier properties of an edible wheat gluten film. Journal of Food Science, Chicago, v. 58, p. 206-211, 1993.

GUILBERT, S.; GONTARD, N. Technology and applications of edible protective films. In: BIOTECHNOLOGY AND FOOD RESEARCH. New shelflife technologies an safety assessments. Helsink (Finland), 1995. p. 49-60.

HOOVER, R. Composition, molecular structure, and physicochemical properties of tuber and root starches: a review. Carbohydrate Polymers, Oxford, v. 45, p. 253$267,2001$.

HOSENEY, R. C. Principios de ciencia y tecnología de los cereales. Zaragoza: Acribia, 1991. $321 \mathrm{p}$.

JANE, J.; CHEN, Y. Y.; LEE, L. F.; McPHERSON, A. E.; WONG, K. S.; RADOSAVLJEVIC, M.; KASEMSUWAN, T. Effects of amylopectin branch chain lenght and amylose content on the gelatinization and pasting properties of starch. Cereal Chemistry, Paul, v. 76, n. 5, p. 629-637, 1999. 
JENKINS, W. A.; HARRINGTON, J. P. Packaging foods with plastics. Lancaster: Technomic publishing, 1991.p. 35-36.

KAPLAN, H. J. Washing, waxing and color adding. In: WARDOWSKI, S.; NAGY, S.; GRIESON, W. (ed). Fresh citrus fruits. Westport: AVI, 1986. p. 379.

KARAM, L. B. Propriedades funcionais de multimisturas de amidos de milho, mandioca e cará e sua relação com as características físicas e moleculares. 2003. Tese (Doutorado em Ciência de Alimentos) - Universidade Estadual de Londrina, Londrina, 2003.

KESTER, J. J.; FENNEMA, O. Edible films and coatings: a review. Food Technology, Chicago, v. 40, n. 12, p. 47-59, 1986.

KUUTTI, L.; PELTONEN, J.; MYLLARINEN, P.; TELEMAN, O.; FORSSELL, P. AFM in studies of thermoplastic starches during ageing. Carbohydrate polymers, Oxford, v. 37, p. 7-12, 1998.

LANDERS, P. S.; GBUR, E. E.; SHARP, R. P. Comparison of two models to predict amylose concentration in rice flours as determined by spectrophotometric assay. Cereal Chemistry, Saint Paul, v. 68, n. 5, p. 545-548, 1991.
LÖRCKS, J. Properties and applications of compostable starch-based plastic material. Polymer Degradation and Stability, Essex, v. 59, p. 245-249, 1998.

MALI, S.; KARAM, L. B.; RAMOS, L. P.; GROSSMANN, M. V. E. Relationships among the composition and physicochemical properties of starches with the characteristics of their films. Journal of Agricultural and Food Chemistry, Easton, v. 52 n. 25, p. 7720-7725, 2004.

SOUZA, R. C. R.; ANDRADE, C. T. Investigação dos processos de gelatinização e extrusão de amido de milho. Polímeros, São Carlos, v. 10, p. 24-30, 2000.

YOUNG, H. Fractionation of starch. In: WHISTLER, R. L.; BeMILLER, J. N.; PASCHALL, E. F. (ed). Starch Chemistry and Technology. 2. ed. Orlando: Academic Press, 1984. p. 249-283.

WURZBURG, O. B. Modified Starches: properties and uses. Boca Raton: CRC Press, 1986. p. 41-53. 